\title{
Libertad vs. Populismo punitivo: ¿deben respetarse los derechos humanos en el proceso penal? A propósito de la nueva declaratoria de estado de cosas inconstitucionales para el sistema penitenciario y carcelario colombiano ${ }^{1}$
}

Freedom vs. punitive populism: should Human Rights be respected in criminal proceedings?

En la Carta del Santo Padre Francisco a los participantes en el XIX Congreso Internacional de la Asociación Internacional de Derecho Penal y del III Congreso de la Asociación Latinoamericana de Derecho Penal y Criminología (Vaticano, 30 de mayo de 2014), el Papa habla de cómo "el Derecho penal requiere un enfoque multidisciplinar, que trate de integrar y armonizar todos los aspectos que confluyen en la realización de un acto plenamente humano, libre, consciente y responsable”.

Rubio (2015)

1 Artículo producto del proyecto de investigación Impunidad en el proceso penal colombiano. Este artículo se gestó en la ONG Fundación Puniendi - Corporación Universitaria Republicana.

2 Magister en Intervención Social en las Sociedades del Conocimiento, UNIR-Espańa; Especialista en Informática Educativa, Universidad Libre, y en Pedagogía para la Docencia Universitaria, Fundación Universitaria del Área Andina; Abogada, Corporación Universitaria Republicana; Licenciada en Ciencias Sociales, Universidad Distrital Francisco José de Caldas, y profesora en la Universidad Escuela Colombiana de Carreras Industriales. Correo electrónico:gloriainesromero@yahoo.com.mx 


\title{
RESUMEN
}

Esta investigación muestra cómo la necesidad de disminuir los índices delincuenciales en el país ha venido justificando de manera soterrada la "relativización de los derechos humanos". Para esto, se parte de la hipótesis de que el hacinamiento carcelario obedece a la adopción de medidas penales que buscan impresionar a la sociedad, pero que carecen de sustento científico, por lo cual su aplicación ha venido perdiendo efectividad como factor de control social. Con base en esto, se demuestra la importancia de diseńar políticas públicas integrales que disminuyan los niveles de criminalidad y la urgencia de realizar programas que aseguren el respeto de los Derechos Humanos de la población carcelaria.

Palabras clave: derecho penal, población carcelaria, política criminal, estado de cosas inconstitucionales (ECI), Fiscalía General de la Nación.

\begin{abstract}
This research focuses on showing how the need to reduce crime rates in the country has been justifying the "relativization of human rights", based on the hypothesis that prison overcrowding is due to the adoption of criminal measures that have As a basis to impress society but lack the sufficient scientific support for its application has been losing effectiveness. With the aim of demonstrating the importance of designing comprehensive public policies that reduce levels of crime and the urgent need to carry out programs that ensure respect for the human rights of the prison population.
\end{abstract}

Keywords: criminal law, prison population, criminal policy, Unconstitutional State of Things (ECI), general prosecutor of the nation

\section{INTRODUCCIÓN}

Dentro del proyecto Impunidad en el proceso penal colombiano se decidió efectuar una investigación documental tendiente a fijar los efectos negativos del uso con fines elec- 
torales del derecho penal colombiano en la construcción de los tipos penales, lo cual ha generado el crecimiento del hacinamiento carcelario y la consecuente violación de importantes derechos fundamentales al interior de los sitios de detención como resultado de la falta de una política pública criminal integral para el tratamiento del delito y de la ausencia de planes concretos de prevención del mismo. Se toma como eje del análisis de este estudio, la reciente declaratoria de estado de cosas inconstitucionales (ECI) del sistema penitenciario hecha por la Honorable Corte Constitucional en la Sentencia T-762/15 en la que se reitera nuevamente cómo la violación de los Derechos Humanos que genera el hacinamiento carcelario es el efecto del auge del populismo punitivo con el cual se pretende solucionar los problemas de inseguridad y los altos índices de criminalidad de la sociedad colombiana a partir de la creación de nuevos, variados y drásticos tipos penales.

Este artículo consta de cinco partes. En la primera, se presenta la pregunta de si deben respetarse todos los Derechos Humanos en el proceso penal. En la segunda parte se expone el panorama carcelario descrito por la Sentencia T-762/15 de la Corte Constitucional. En la tercera parte se resume la problemática estructural del sistema carcelario y penitenciario colombiano; en la cuarta parte se define de manera propositiva el papel de la Fiscalía General de la Nación en el diseño de la política criminal $y$, finalmente, en la quinta parte, se trazan unas conclusiones respecto del problema planteado para este escrito.

\section{1. ¿Deben Respetarse todos los Derechos Humanos en el PROCESO PENAL?}

Aunque inicialmente parezca satírico o por lo menos de obvia respuesta preguntarnos, en la segunda década del siglo XXI, si deben respetarse los Derechos Humanos en el proceso penal, lo cierto es que tanto la sociedad colombiana como la sociedad mundial, ante el temor del terrorismo y el sentimiento de impotencia del sistema jurídico para procesar, condenar y hacer que responda por sus actos la criminalidad organizada que se manifiesta de diversas maneras delictivas en el orden nacional y local, han venido apoyando de manera disfrazada la adopción de medidas desproporcionadas contra los criminales, especialmente en lo referente a la aceptación de tipos 
penales en los que se pasan por alto importantes garantías ciudadanas (Basombrío \& Dammert, 2013, p. 1).

En Colombia tal tendencia se manifiesta en excesos en la restricción de la libertad de las personas sindicadas, el hacinamiento carcelario, el aumento en el índice de construcción de penitenciarias y el desconocimiento al interior de las mismas de un sinnúmero de Derechos Humanos para quienes están presos, al tiempo de influir en la congestión en el sistema judicial propiciándose con ello trabas que impiden la celeridad de la justicia y aumentan los índices de impunidad.

Así lo señala la Sentencia T-762/15 de la Corte Constitucional en que se indica que el desconocimiento masivo y generalizado de los derechos fundamentales de las personas privadas de la libertad ha desencadenado el uso, "también masivo, de la acción de tutela, como medio de defensa de los afectados" (Corte Constitucional, Sentencia T-762/15, p. 75), aumentándose aún más la congestión del aparato judicial. En la Sentencia T-762/15 del 16 de diciembre de 2015, M.P. Gloria Stella Ortiz Delgado, la Sala Quinta de Revisión de la Corte Constitucional reitera el estado de cosas inconstitucionales (ECI), declarado anteriormente en las sentencias T-153 de 1998 y T-388 de 2013. Sin embargo, esta vez la Sala de revisión centra su atención en el respeto a los Derechos Humanos de la población carcelaria nacional a partir de los fallos judiciales sobre dieciséis centros de reclusión de diferentes partes del país. En esta nueva declaratoria de ECI para el sistema penitenciario y carcelario, la Sala indica que el desconocimiento a los Derechos Humanos de las personas privadas de la libertad obedece en Colombia a una problemática estructural que se manifiesta en, p. 1) la desarticulación de la política criminal y el ECI, 2) el hacinamiento y otras causas de violación masiva de derechos, 3) la reclusión conjunta de personas sindicadas y condenadas, 4) la falta de articulación de las entidades territoriales y el Ministerio de Justicia y del Derecho, 5) las debilidades del sistema de salud del sector penitenciario y carcelario del país y 6) en las deplorables condiciones de salubridad e higiene en la mayoría de los establecimientos penitenciarios, lo que constituye un trato cruel e inhumano propiciado por el Estado ante el cual el alto tribunal profiere ciertas órdenes generales, particulares y relativas a cada caso en concreto estableciendo el procedimiento, la documentación requerida y los topes de calificación, precisando a la manera de ver de la autora de este artículo demasiadas especificaciones que si bien buscan establecer unos estándares mínimos, en el futuro tales estándares pueden con- 
vertirse en trabas irremediables en la consolidación de políticas públicas respetuosas de los Derechos Humanos de las personas privadas de la libertad. En la Sentencia T-762/15 se determina que:

El objetivo primordial de la reiteración del ECI es la consecución de un sistema de gestión público armónico, que tenga posibilidad de actuar en forma autónoma para restablecer los derechos de la población privada de la libertad. Para tal efecto se estructurarán objetivos claros frente a cada problema detectado, que se acompañan de lineamientos puntuales de gestión, ofreciendo parámetros específicos de acción administrativa y de evaluación del ECI (Sentencia T-762/15, p. 135).

En concordancia con lo dispuesto anteriormente, es importante resaltar lo dispuesto por la profesora Carreño, quien ha considerado que "para un análisis de las complejidades del delito de tortura en Colombia, es necesario señalar al menos brevemente, el escenario y el contexto en donde esta se produce y se reproduce" (Carreño, 2016, p. 125).

Para comprender el panorama penitenciario y carcelario actual en Colombia, cabe mencionar cómo se han adoptado algunas medidas legislativas tendientes a limitar la adopción y duración de la detención preventiva en cumplimiento de la Sentencia C-390/14, tal como sucede con la Ley 1760 de 2015 en la que en el primer artículo se establece que las medidas de aseguramiento privativas de la libertad no podrán exceder de un año y que para su imposición, quien las solicite debe probar ante el juez correspondiente que las no privativas de la libertad resultan insuficientes para garantizar el cumplimiento de los fines de la medida de aseguramiento.

Dicha Ley, en el artículo 2. ${ }^{\circ}$, adiciona al artículo 308 de la Ley 906 de 2004 un parágrafo en el que le exige al juez de garantías no centrarse exclusivamente en la conducta punible que se investiga para inferir el riesgo de obstrucción de la justicia, el peligro para la seguridad de la sociedad o de la víctima y la probabilidad de que el imputado no comparezca al proceso o de que no cumplirá la sentencia; en el artículo $4 .^{\circ}$ numeral $6{ }^{\circ}$ indica que si transcurridos 150 días a partir de la fecha de inicio de la audiencia de juicio sin que se haya celebrado la audiencia de lectura de fallo o su equivalente, se procederá a la libertad del imputado o acusado de inmediato, resal- 
tando por último el artículo $5 .^{\circ}$ que el numeral $6 .^{\circ}$ del artículo $4^{\circ}$ solo entrará a regir un año después de la fecha de su promulgación.

La Ley 1760 fue impulsada por el Ministerio de Justicia y la Fiscalía para definir la situación de cerca de 43.000 personas detenidas preventivamente, de las cuales un número considerable llevan varios años tras las rejas sin que se les defina su situación jurídica y también se diseńó como un mecanismo para frenar las multimillonaria cifra de las demandas contra el Estado de las víctimas de las medidas de detención sin la suficiente carga probatoria, "más de 18.000 personas que han sido absueltas han demandado al Estado" y "la suma de las indemnizaciones asciende a unos 23 billones de pesos (Semana, 2015).

En la presentación de la ley, el ministro de Justicia resaltaba que el Estado colombiano "no puede esperar diez años para decirle a una persona a la que le quitó la libertad 'qué pena, me equivoqué" (Semana, 2015). Sin embargo, aunque la Ley 1760 buscaba evitar los abusos que el actual proceso penal permite en el país, el Congreso aprobó recientemente unas medidas tendientes a evitar que se diera cumplimiento al límite temporal del numeral $6 .^{\circ}$ del artículo $4 .^{\circ}$ de la Ley 1760 (El Tiempo, 2016). Es decir, nuevamente el populismo punitivo muestra su cara en el recinto del Congreso por lo que toma un nuevo aire la "idea de que un carcelazo es sinónimo de justicia" (Semana, 2015), pasándose por alto que teóricamente la detención preventiva es una medida muy excepcional en nuestro país (Semana, 2015) y sirviendo las leyes penales para que algunos políticos faltos de programas sociales busquen ganar puntos con el electorado. "Es muy fácil formular un proyecto de ley por cada escándalo, pero eso no lo resuelve sino que lo agrava" (Semana, 2015).

La Sala, en la Sentencia T-762/15, al declarar el ECI para la población penitenciaria y carcelaria resalta que en el país se requiere el diseño de una política criminal sistematizada y coherente al tiempo de realizar acciones sociales con las que se concientice a la sociedad en la comprensión sobre el por qué solo excepcionalmente se debe restringir la libertad a una persona procesada penalmente, resaltando que en la actualidad la injerencia de los medios de comunicación masivos ha sido decisiva 
para la promulgación de ciertas posturas de populismo punitivo con las que se busca desconocer una serie de derechos fundamentales de la Constitución Política de 1991 y que la presión de la prensa ha llevado en algunas ocasiones a que los jueces declaren detenciones preventivas sin que sean realmente necesarias, en lo que algunos penalistas como Zaffaroni y Ferrajoli denominan justicia espectáculo (Semana, 2015).

Para la Corte, tanto el Congreso como el Gobierno nacional y los demás responsables de la formulación y diseño de la política criminal han venido adoptando decisiones de forma reactiva y sin fundamentos empíricos sólidos, decisiones apresuradas por la necesidad de mostrar celeridad a la opinión pública frente a ciertos delitos de alto impacto, buscando con ello aumentar la popularidad en algunos sectores políticos pero que no tienen como meta impactar los índices de criminalidad y solo en contadas ocasiones se "sostienen en fundamentos sólidos que permitan relacionar la expedición de una norma y la reducción real de un fenómeno criminal" (Sentencia T-762/15, p. 81). Dada la importancia que la Sala de revisión le da a la tarea de reformular la política criminal en Colombia para evitar que se continúen violando los derechos fundamentales de la población recluida en el país, cabe preguntarse cuál debe ser la función del nuevo fiscal general de la nación frente al tema.

La Fiscalía General de la Nación (FGN) es un organismo independiente adscrito a la rama judicial creada por la Constitución Nacional de 1991, al que se encargó de retomar las acciones que adelantaba la antigua Dirección Nacional de Instrucción Criminal. La forma de elección del fiscal general de la nación, sus funciones generales y especiales están contempladas en la Constitución de 1991, en el Capítulo 6. De la Fiscalía General de la Nación, Título VIII. De la Rama Judicial de la Constitución Política que en el artículo 249 indica cómo se elige al fiscal general de una terna que el presidente de la república le presenta a la Corte Suprema de Justicia y aclara que la FGN hace parte autónoma de la rama judicial. En el artículo 250 se contemplan las funciones de la FGN y en el artículo 251, modificado por el artículo 3. del Acto Legislativo $N .^{\circ} 3$ de 2002 , se señala en el numeral $4 .^{\circ}$ que una de las funciones especiales del fiscal general de la nación es la de "participar en el diseño de la política del Estado en materia criminal y presentar proyectos de ley al respecto" (Const., 1991). 


\title{
2. Panorama carcelario descrito en la Sentencia t-762/15 DE LA CORTE Constitucional
}

\author{
Se trata de hacer justicia a la victima, \\ no de ajusticiar al agresor. \\ Rubio E. (2015)
}

En la Sentencia T-762/15, los accionantes denuncian la violación sistemática de los derechos fundamentales de la población privada de la libertad en el país. "El principal reclamo se relaciona con las condiciones de reclusión que se ofrecen en las cárceles, descritas por los inconformes como 'inhumanas', 'tortuosas' y 'violatorias de la dignidad humana" (T-762/15, p. 59) y en las acciones de tutela, base de la revisión hecha por la Sala, se alerta sobre el alto índice de hacinamiento al que están sometidas las personas privadas de la libertad, las condiciones sépticas e infrahumanas en las cuales se encuentran recluidos los accionantes, debido principalmente a la deficiente infraestructura y sus efectos en las condiciones sanitarias, la falta de servicios asistenciales de salud, la imposibilidad de realizar actividades tendientes a su resocialización dada la sobrepoblación carcelaria reinante, la falta de intimidad en el desarrollo de las visitas conyugales y la reclusión conjunta e indistinta de las personas sujetas a medidas de aseguramiento privativas de la libertad y aquellas condenadas.

En los amparos constitucionales encuentra la Sala que por lo general los tribunales ordenan a los diferentes centros penitenciarios y carcelarios no permitir el ingreso de nuevos reclusos cuando se exceda su capacidad locativa, que se trasladen los internos a otros establecimientos para evitar la sobrepoblación, se mejoren estructuralmente los establecimientos de reclusión conforme a las exigencias mínimas de la dignidad humana y se presten los servicios de salud, sanitarios, de agua potable y de alimentación conforme a los requerimientos propios de la vida humana. La Sala de revisión en la determinación de los índices de hacinamiento de los lugares de reclusión de los dieciséis centros penitenciarios y carcelarios en los que se sustenta la sentencia T-762/15, se documentó con los informes entregados por la Defensoría del Pueblo, la Procuraduría General de la Nación, las personerías municipales y los despachos judiciales que efectuaron inspecciones judiciales a los sitios de reclusión en los que se encontraban los accionantes. 
Dentro de los documentos allegados, están la intervención del director nacional y algunos de los directores regionales del Instituto Nacional Penitenciario y Carcelario (INPEC), que afirman que la capacidad carcelaria del país es para 75.726 cupos y que en la actualidad se albergan alrededor de 117.000 internos aproximadamente. Según la Defensoría del Pueblo, "nunca en la historia del país la problemática carcelaria fue tan grave como la que hoy afrontamos" (Defensoría del Pueblo, 2015, p. 2) ya que la sobrepoblación carcelaria en 2014 bordeó el $60 \%$ a nivel nacional y el 31 de diciembre de 2014 había un sobrecupo de 35.749 reclusos, equivalente al 45,9\% (Defensoría del Pueblo, 2015, p. 2). Y el informe estadístico de enero de 2015 del INPEC afirma que al finalizar enero de 2015, se registró una capacidad para 77.874 internos y para ese mismo mes en el país existían 161.477 personas privadas de la libertad, más del doble de la capacidad del Instituto (INPEC, 2015, p. 14-15).

Además, en sus manifestaciones a la Sala, los funcionarios del INPEC indicaron que el problema de hacinamiento carcelario no se solucionaba con las medidas adoptadas por algunos jueces de cerrar los centros penitenciarios y carcelarios y/o con el traslado de reclusos a otros centros penitenciarios, ya que con ello se afecta "la seguridad, el bienestar general y los derechos de los internos de otros establecimientos" (T$762 / 15$, p. 61). Opinan los funcionarios del INPEC que para evitar el incremento de la población carcelaria en el país, las autoridades encargadas deben comprometerse en la formulación de una política criminal estructurada en la que se fijen parámetros con los que se reduzca la población carcelaria, resaltando la importancia de fomentar el uso de mecanismos de vigilancia alternativos al de la privación de la libertad.

Para comprender las pésimas condiciones en las que se encuentran las personas detenidas en el país, baste mencionar, por ejemplo, lo expuesto en el expediente T-3987203 para la cárcel "La 40" de Pereira, donde se describe la precaria e inhumana crisis sanitaria de algunos patios en los que solo tienen "una sola ducha para casi 800 presos" y cuentan con "tres baños/sanitarios" para todos los detenidos y "la infestación de roedores (ratas) y otros bichos (cucarachas, chinches) es aterradora" (T-762/15, p. 17), concluyendo los accionantes que por las condiciones en las que se encuentran no están pagando una pena sino "una tortura... sin oportunidad de resocialización" (p. 17).

También el director de la cárcel de Santa Rosa de Cabal, dentro del expediente T-3989532, manifiesta que pese a que la capacidad física de ese sitio es para 121 
personas, en la actualidad el número de internos es de 254 y que aunque en 2013 se gestionó el traslado de 49 internos y se tramitó diariamente diversas solicitudes de libertad condicional, libertad por pena cumplida y otros beneficios administrativos, la gran mayoría fue negada por los jueces de ejecución de penas debido a la gravedad de las conductas y/o el no pago de las multas necesarias (T-762/15, p. 21). Una de las denuncias más alarmantes es la narrada en el expediente T-4009989 en que el accionante solicita la protección de sus derechos a la vida y a la dignidad humana afirmando que aunque no ha sido condenado porque su situación jurídica es la de sindicado, debido al hacinamiento de alrededor del $300 \%$ de la Cárcel Modelo de Bogotá, está "durmiendo en el suelo con una cobija a orillas de los baños, al pie de las basuras" (T-762/15, p. 31).

Sin embargo, el problema no es solo de cupos por lo que la Sala, en la Sentencia T-762/15, deja claro que la crisis carcelaria no exige únicamente la creación de nuevos centros de reclusión sino que se mejoren las condiciones de vida en cada uno de los existentes con el fin de evitar que se sigan violando de manera sistemática los derechos fundamentales de la población carcelaria. Y es que, por ejemplo, en el caso del expediente T-3989814 sobre el establecimiento penitenciario de mediana seguridad y carcelario (EPMSC) El Pedregal de Medellín, uno de los establecimientos con menos índice de hacinamiento del país, que tiene capacidad para 208 internos distribuidos en celdas para cuatro individuos y las cuales actualmente están ocupadas por cinco personas, su principal problema no está en el hacinamiento sino en las condiciones locativas nocivas para la salud al no tener los internos acceso a la "luz solar... ya que esta estructura no cuenta con patios de sol, lo cual viola claramente el derecho a la dignidad humana" (T-762/15, p. 24). En la respuesta del director del centro de reclusión se indica que todos los pabellones tienen rejillas que permiten el ingreso directo de iluminación natural, pero la Personería de Medellín manifestó que la situación de salud de los reclusos es impresionante al no contar con servicios ni medicamentos adecuados. "En cuanto a la luz solar, certificó que el pabellón de hombres es completamente cerrado y no hay ingreso de iluminación natural suficiente" (2015, p. 26). A instancia de la Sala de revisión, el Instituto de Medicina Legal describió de manera genérica los efectos que trae para el ser humano el no contar con luz solar señalando que:

Las dosis moderadas de luz solar traen efectos positivos sobre el ser humano pues permiten al cuerpo mantener los niveles necesarios de vitamina $\mathrm{D}$, mien- 
tras que la exposición excesiva trae efectos nocivos sobre la salud, la ausencia de iluminación solar influye negativamente sobre el estado de ánimo y afecta la capacidad del cerebro para el manejo de información, la luz solar influye en la producción de hormonas en el individuo. Y aclara que el Instituto de Medicina Legal desconoce las condiciones de los reclusos de ese centro de reclusión, por lo cual no hace mayores precisiones sobre el caso concreto (T$762 / 15$, p. 28).

Los integrantes del semillero de investigación interuniversitario sobre el Castigo y el Derecho Penal de EAFIT opinan que las condiciones de los establecimientos penitenciarios en Medellín no permiten que la pena cumpla su fin resocializador, ya que según sus investigaciones el complejo El Pedregal está diseñado a partir de los parámetros de la industria penitenciaria norteamericana, presentando una estructura rígida, cerrada y antifuga, bajo el modelo terapéutico y resocializador apoyado en el ascetismo y el aislamiento, modelo que en su concepto no es viable "debido al hacinamiento, a la ausencia de disciplina y orden, a la falta de reglas y a los problemas de convivencia" (Sentencia T-762/15, p. 29) que presenta el centro de reclusión. Es decir, el problema del hacinamiento en los sitios de reclusión en el país exige que se evalúa el sistema carcelario que se ha venido adoptando, más si se tiene en cuenta que el "crecimiento de la población penitenciaria presenta una velocidad mayor de la que ha podido tener la generación de cupos" (Ministerio de Justicia y del Derecho Dirección de Política Criminal y Penitenciaria, 2014, p. 68).

La Sala de revisión, desde una mirada más amplia de las necesidades del sistema carcelario, identifica en la sentencia T-762/15 tres subproblemáticas derivadas del hacinamiento, p. 1) la relacionada con la desproporción entre las entradas y salidas de personas privadas de la libertad a los centros de reclusión, 2) la relacionada con la construcción de cupos carcelarios y penitenciarios que no respetan estándares mínimos de dignidad humana y 3) la forma como se han invertido los recursos, ya que hasta ahora se han usado fundamentalmente para afrontar la sobreocupación carcelaria en el país. Las tres subproblemáticas mencionadas, opina la Sala, dan muestra del desconocimiento de varios derechos fundamentales para la mayoría de la población privada de la libertad y justifican la reiteración de la declaración de ECI para el sistema penitenciario colombiano, haciéndose improrrogable la evaluación de la inversión de los recursos destinados para el sistema carcelario, pues hasta ahora se ha 
centrado en la construcción de nuevas edificaciones en las que no se ha tenido en cuenta en su diseńo el respeto de la dignidad humana y el derecho a la salud de los reclusos.

Estas inversiones no han buscado dar una respuesta integral debido a que han sido formuladas a partir de una política criminal no sistematizada, como ya lo había advertido la Defensoría del Pueblo en el informe presentado con ocasión de la Sentencia T-388 de 2013, en el que resaltaba que la solución al hacinamiento penitenciario no radicaba en la construcción de nuevos establecimientos carcelarios y en la reparación de los existentes, sino que existían otros factores como la creación constante de nuevas conductas punibles, el abuso de la privación de la libertad como medida de aseguramiento, la incorrecta aplicación de las normas vigentes encaminadas a la reinserción social del condenado y a evitar su reincidencia en el delito, así como el auge de una política criminal y penitenciaria represiva que afectaba el tratamiento progresivo para la reinserción del recluso, la atención en salud dentro de las prisiones y la ampliación de la planta de personal administrativo, de custodia y vigilancia dentro del sistema carcelario para hacerlo más eficiente.

El problema carcelario requiere desde hace mucho tiempo, más asignación de partidas del presupuesto nacional para construcciones y refacciones, y con igual urgencia exige una atención integral, para lo cual es necesario establecer una mayor coordinación entre los poderes legislativo, ejecutivo y judicial con el fin de adoptar las políticas que permitan enfrentar y solucionar la crisis carcelaria a corto y mediano plazo (Sentencia T-388/13, p. 49).

\title{
3. Problemática estructural del sistema carcelario y PENITENCIARIO COLOMBIANO
}

\author{
Abre epígrafe Para Francisco "sería un error identificar la reparación solo con \\ el castigo, confundir la justicia con la venganza, lo que solo contribuiría a \\ incrementar la violencia, aunque esté institucionalizada".
}

Wemer (2014) 
La Sala Quinta de Revisión de la Corte Constitucional, en la Sentencia T-762/15 subraya que la constatación de la vulneración constante y sistemática de los derechos fundamentales de las personas privadas de la libertad exige el reconocimiento de una complejidad que lejos de ser esporádica ha venido convirtiéndose en un asunto estructural en el que la desarticulación de la política criminal del país orquestada por el populismo punitivo se manifiesta en una tendencia creciente de endurecimiento punitivo, en la creación de nuevas conductas penales, el incremento en las penas para los delitos existentes y en el aumento de las personas privadas de la libertad (T-762/15, p. 83). El auge del populismo punitivo ha provocado que la prisión sea cada vez más el eje de la política criminal y parte de la sensibilización de la opinión pública a través de los medios de comunicación promocionando las posturas de algunos políticos que por cuestiones electorales abogan por la adopción de medidas legislativas coyunturales con las que se busca satisfacer las "impresiones mayoritarias, momentáneas y circunstanciales, sobre las necesidades de la sociedad, en detrimento del valor constitucional de la libertad" (T-762/15, p. 85) y que parten de una supuesta relación no probada del aumento de las penas con la reducción del delito, aunque el trasfondo simplemente "sea sacar partido en sus intereses particulares y convertir el tema penal en un instrumento que permita alcanzar aspiraciones políticas" (Cotes \& Fuentes, s.f., p. 69).

En términos generales, puede decirse que el populismo punitivo más que interesarse en frenar el delito, lo que hace es sensibilizar a la opinión pública sobre un asunto mediático "despojándose de una articulación más compleja que proponga hacer frente al problema de la criminalidad” (Cotes \& Fuentes, s.f., p. 65). La utilización de la estructura penal para fines electorales ha tenido también como efecto que se supedite la política criminal a la de seguridad, dando como resultado la crisis actual del sistema penitenciario y carcelario (T-762/15, p. 86). Y si bien en 2010, el Gobierno nacional gestionó algunas acciones tendientes a consolidar una política pública dentro del Plan Nacional de Desarrollo 2010-2014, intentando crear un sistema que permitiera coordinar a todos los intervinientes en la formulación de la política criminal en la adopción de los procesos de evaluación de resultados y de rendición de cuentas sobre los alcances de la misma, con el fin de "disminuir la impunidad y fortalecer la convivencia, la inclusión y la seguridad” (T-762/15, p. 87), enmarcando tales acciones en la consolidación de la paz y la eficacia de la justicia (DNP, 2010, p. 
29), es menester señalar que en realidad en Colombia la impunidad no ha disminuido y muestra de ello es que fue el tercer país con mayor impunidad en el mundo en 2015, según un estudio realizado por la Universidad de Las Américas, de Puebla de México (Udlap) que dentro del análisis científico detectó que el país tenía "un índice de 75,6 puntos, en relación con 59 países que han reportado ante Naciones Unidas estadísticas de sus indicadores en los tres aspectos que se estiman contribuyen a la impunidad en el mundo" (El Universal, 2015).

Otras iniciativas gubernamentales encaminadas a fortalecer la política criminal que vale la pena resaltar en 2015 son la impulsada por el Ministerio de Justicia y del Derecho para la expedición de dos documentos CONPES sobre el tema y la Ley del Plan Nacional de Desarrollo 2014-2018, Ley 1753 de 2015, en la que se destinaron recursos para la política criminal con enfoque restaurativo (Sentencia T-762/15, p. 87). Ahora es claro que si bien el Plan Nacional de Desarrollo 2014-2018 traza acciones tendientes a lograr que la política criminal se modernice y tenga un mayor sustento científico como lo es el "definir políticas ambiciosas que permitan avanzar hacia una justicia más eficiente y al día” (DNP, 2010, p. 29), lo cierto es que en la realidad la desconfianza en la administración de justicia es alta y, según Leonardo Rodríguez, los estudios arrojan que en el país existe desconfianza hacia los funcionarios que imparten la justicia, percepción sobre la corrupción en la justicia, sobrecarga de expedientes por parte de las autoridades judiciales, falta de asignación de recursos presupuestarios indispensables, los procesos son costosos y dispendiosos, hay poca relación entre la pena y el daño causado a las víctimas, las penas no cumplen con su papel de resocializar a la persona a la sociedad, las víctimas en el proceso judicial se sienten abandonados y las normas jurídicas no atienden en la mayoría de ocasiones a estudios de viabilidad y factibilidad desde las diferentes instituciones académicas (Rodríguez, 2015). Además, dificultan la eficacia y eficiencia en la justicia las reformas penales de los últimos años que no han estado acompañadas de un aumento suficiente de personal en la rama judicial.

En efecto, a partir del estudio realizado, la Comisión encontró que desde 2000 hasta 2011, las principales modificaciones a la legislación penal existente, p. 1) crearon 47 nuevos tipos penales; 2) aumentaron las penas de 80 delitos existentes; y 3) incrementaron el número de personas privadas de la libertad en las cárceles, no solo en 
términos netos, sino también en proporción a la población colombiana, toda vez que "el número de personas privadas de la libertad se triplicó entre 1992 y 2010, pues pasó de unos 27.000 a más de 81.000 , mientras que la tasa por cien mil habitantes se incrementó también considerablemente, multiplicándose por aproximadamente 2,5, pues pasó de 79,9 a 178,2" (T-762/15, p. 83).

No solo agrava el hacinamiento en el sistema penitenciario y carcelario la diversidad de los tipos penales y el recrudecimiento de las penas, sino que es un factor altamente sensible el relacionado con el uso de la detención preventiva "como una herramienta de investigación, y no como un mecanismo restringido para salvaguardar a la comunidad" (T-762/15, p. 90). La aplicación de tal medida, según el informe del Ministerio de Justicia y del Derecho, representa un porcentaje alto de la población reclusa, ya que de 119.378 personas privadas de la libertad a cargo del INPEC, el $38 \%$ de esa población, es decir 44.322, son sindicados (T-762/15, p. 90). Pero además de aumentar el hacinamiento, la aplicación de esta medida genera altos riesgos para los derechos de la población reclusa y una alta inversión patrimonial en la atención y pago de demandas y condenas contra el Estado como consecuencia del uso desmedido de la prisión como medida de aseguramiento. "Para el año 2014, cursaban 18.797 procesos por privación injusta de la libertad, cuyas pretensiones ascendían a 23,9 billones de pesos". (T$762 / 15$, p. 90) y como lo señala la CIDH sobre la detención preventiva, esta "no es una medida que contribuya de manera exitosa a reducir los índices de violencia y criminalidad" (CIHD 2014) y en cambio agrava la situación del respeto a los Derechos Humanos que ha venido adoptándose cada vez más en todos los países de América.

En la absoluta mayoría de los Estados miembros de la OEA, las personas en prisión preventiva están expuestas a las mismas o peores condiciones que las personas condenadas; sufren grandes tensiones personales como resultado de la pérdida de ingresos y de la separación forzada de su familia y comunidad, y están expuestas al entorno de violencia, corrupción, insalubridad y condiciones inhumanas presentes en las cárceles de la región (CIHD 2014).

En la segunda problemática detectada en la Sentencia T-762/15 denominada hacinamiento y otras causas de violación masiva de Derechos, la Sala centra su atención en la descripción de las consecuencias directas del hacinamiento carcelario sobre la dignidad de las personas privadas de la libertad provocando una vulneración siste- 
mática de sus derechos con situaciones de ingobernabilidad y violencia que muchas veces atentan contra la vida y la integridad de los presos, propiciando nichos para la propagación de enfermedades y epidemias que hacen casi imposible la realización de programas sostenibles de resocialización o de redención, lo cual se agrava aún más por la falta de políticas claras de sustitución de la pena.

Además, la carencia de información fiable en lo concerniente a la capacidad real de los establecimientos carcelarios y penitenciarios ahonda la crisis del sector al hacer más difícil la definición de directrices con fundamentos empíricos apropiados a la realidad nacional, pues aunque hay fiabilidad en los datos sobre el número de personas recluidas, los rangos de edad y las actividades de resocialización "no son fiables en lo concerniente a la capacidad real de los establecimientos" (T-762/15, p. 110), lo cual impide precisar las carencias existentes, y su medición no es tan sencilla ya que no existen especificaciones claras que permitan establecer las condiciones de las celdas, el número de camas disponibles y de las instalaciones sanitarias, entre otros aspectos necesarios para trazar tareas que corrijan el hacinamiento.

Es por ello que la Sala, teniendo en cuenta las imprecisiones encontradas para calcular la capacidad de albergue de cada sitio de reclusión, exige se establezcan unos estándares con el fin de medir "la aptitud de las instalaciones y de la gestión del espacio y de los internos" (T-762/15, p. 110) y a partir de ellos trazar programas tendientes a satisfacer las condiciones de subsistencia digna y humana a todos los reclusos para garantizarles el derecho a "la vida digna; además, deriva en la imposición de unas directrices para la construcción de cupos carcelarios a futuro" (T-762/15, p. 111). Entendiendo que los estándares mínimos deben trazarse con base en la realidad actual de los sitios de reclusión y con los establecidos en el ámbito internacional al respecto, por lo que en las órdenes generales de la T-762/15 encarga a la Defensoría del Pueblo determinar las condiciones de vida y de gestión que implica un cupo carcelario digno (T-762/15, p. 129) partiendo de la idea que tal definición es una exigencia mínima para corregir la violación sistemática de derechos fundamentales en el sistema penitenciario colombiano, más si se tiene en cuenta el elevado número de personas afectadas hasta el momento.

Según el INPEC (2015), en enero de 2015 se registraban 161.477 personas privadas de la libertad de las cuales el 97,7 \% estaba a cargo del INPEC y el restante 2,3\% 
bajo la custodia y responsabilidad de los entes territoriales, comandos de fuerza y dirección general de la Policía Nacional. De las 157.693 personas a cargo del INPEC, 116.760 estaban en centros de reclusión; 36.587, en domiciliaria y 4.346, con control y vigilancia electrónica, datos que permiten concluir que la gran mayoría de la población carcelaria se encontraba en los centros de reclusión y representaba el $72,3 \%$ de la misma; que el $22,7 \%$ estaba en domiciliaria y que era mínima la población con control de vigilancia electrónica al representar tan solo el 2,7 \%, es decir que para 2015 primaba la cárcel como sanción penal apartándose de los fines propios de un Estado social de derecho, de las de resocialización del delincuente y de los precedentes jurisprudenciales que abogan por "la humanización del derecho penal” (Corte Constitucional, Sentencia C-425/08, p. 78) y por una política penitenciaria "respetuosa de las garantías de la población privada de la libertad, racional, coherente y coordinada con la política penitenciaria" (Ministerio de Justicia y del Derecho, 2014, p. 5).

Y mientras la jurisprudencia aboga por la adopción de medidas alternas a la sanción penal intramural y aboga que se asegure una reinserción del recluso a la sociedad (Corte Constitucional, Sentencia T-035/13, p. 24), en la realidad la adopción de la medida intramural sigue creciendo; ejemplo de ello es que en enero de 2015, el INPEC tenía capacidad para 77.874 internos y se registraba un total de 116.760 internos, cifra que comparada con diciembre de 2014 mostró un incremento de 3.136 personas privadas de la libertad lo cual representaba el 2,76 \% del total de población reclusa y un porcentaje similar al de los cobijados con control de vigilancia electrónica; alcanzándose en ese momento una sobrepoblación de 38.886 personas a cargo del INPEC, lo que significaba un índice de hacinamiento de 49,9 \% (INPEC 2015, p. 18). Y aunque se viene dando un crecimiento en la capacidad de los sitios de reclusión existentes y se están construyendo nuevas obras a disposición del INPEC (INPEC, 2015, p. 18) lo cierto es que representan un porcentaje bastante alto de la población intramural los sindicados que en enero de 2015 llegaron a 37.994 personas (INPEC, 2015, p. 24). Además, las 75.627 personas condenadas en sitio de reclusión (INPEC, 2015, p. 24) se podrían disminuir si se fomentara la aplicación de subrogados penales, mecanismos sustitutivos de la pena y la vigilancia electrónica en el sistema penal colombiano, en el marco de una política criminal coherente con los principios constitucionales y las exigencias jurisprudenciales. 
En múltiples ocasiones, la jurisprudencia constitucional ha planteado que los subrogados penales o mecanismos sustitutivos de la pena, como medidas que permiten reemplazar una pena restrictiva por otra más favorable, tienen como "fundamento la humanización del derecho penal y la motivación para la resocialización del delincuente". Así, la existencia de estos mecanismos se entiende articulada a una política criminal con una orientación humanizadora de la sanción penal, que en el marco del Estado social de derecho debe ser necesaria, útil y proporcionada, para contribuir con los fines de prevención, retribución y resocialización. Esto quiere decir que si los mismos fines pueden lograrse a través de otras figuras, debe preferirse la más favorable para garantizar la dignidad del condenado, puesto que la más restrictiva dejaría de ser necesaria y útil (Ministerio de Justicia y del Derecho, 2014, p. 5).

\section{Papel de la Fiscalía General de la Nación en el diseño de LA POLÍTICA CRIMINAL}

La cautela en la aplicación de la pena debe ser el principio que rija los sistemas penales, y la plena vigencia y operatividad del principio pro homine debe garantizar que los Estados no sean habilitados, jurídicamente o de hecho, a subordinar el respeto de la dignidad de la persona humana a cualquier otra finalidad, incluso cuando se logre alcanzar una especie de utilidad social. El respeto de la dignidad humana no solo debe actuar como límite de la arbitrariedad y los excesos de los agentes del Estado, sino como criterio de orientación para perseguir y reprimir las conductas que representan los ataques más graves a la dignidad e integridad de la persona humana (Rubio, 2015, p. 2).

La Fiscalía General de la Nación (FGN) como parte de la rama judicial surgió con la Constitución de 1991 y es una de las entidades que pueden presentar proyectos de ley sobre política criminal y participar en el diseño de planes estatales sobre la misma. Si se tiene en cuenta que varios directores de centros penitenciarios y de reclusión explican el incremento de la población carcelaria como resultado del aumento en la imposición de medidas de aseguramiento privativas de la libertad, fruto del populismo punitivo, y han recalcado la necesidad de establecer una política criminal en la que se fijen parámetros a fin de reducir la población carcelaria para lo cual estiman 
conveniente "aumentar el uso de mecanismos de vigilancia alternativos, diferentes a la medida de aseguramiento privativa de la libertad" (T-762/15, p. 61). Además, como son los fiscales quienes exigen las medidas de aseguramiento y el cumplimiento de las penas en las cárceles, cabe preguntarse sobre el rol de la FGN en la sociedad colombiana y su posición ante las exigencias populares de punición con las que se han venido controvirtiendo "los postulados libertarios que implica la fórmula del Estado social y democrático de derecho" (T-762/15, p. 115) que ponen en riesgo el respeto de la libertad personal y olvidan el carácter residual del derecho penal, especialmente en los casos en los que las personas están amparadas por la presunción de inocencia.

En definitiva, se trata de hacer un acercamiento al papel que puede ejercer la FGN dentro de la delimitación de una política pública para la política criminal que contribuya en la formulación de medidas tendientes a disminuir el número de personas sindicadas privadas de la libertad y el compromiso estatal de respetar "como regla general la libertad personal" (T-762/15, p. 116), teniendo como meta darle un trato diferente a los sindicados de quienes ya se les ha probado su culpabilidad en la comisión de un delito. $\mathrm{Y}$ a que se destinen programas tendientes a corregir lo máximo posible el impacto negativo de la privación de la libertad de los sindicados en el caso que sean encontrados inocentes para que su incorporación a la sociedad sea lo menos traumática posible, más si se tiene en cuenta que el porcentaje más alto de población sindicada reclusa es adulta en edad productiva.

La población reclusa está discriminada en cuatro grandes rangos etarios. El mayor número de reclusos se ubica en la categoría de 30 a 54 años con 60.829 (52,1\%); en segundo lugar se hallan quienes tienen entre 18 y 29 años, 49.095 (42,0 \%). Las personas entre 55 y 64 años ocupan el tercer renglón con 5.037 (4,3\%) y finalmente, 1.799 (1,5\%) personas mayores de 65 años. En cada una de estas categorías, los hombres superan el $92 \%$ de participación (INPEC, 2015, p. 25).

Dado el incremento alarmante de la adopción de medida de aseguramiento intramural que se ha descrito anteriormente, lo cual como también se ha mencionado está influenciado directamente por el populismo punitivo que encuentra como camino para disminuir la delincuencia la aplicación de la cárcel como castigo y el aumento de presencia policial para evitar el crimen, otro factor que debe tenerse en cuenta es el descrédito que ha venido sufriendo la administración de justicia que en palabras 
de Jairo Libreros, especialista en seguridad, se expresa en un descontento social "que haría que la gente ya no esté interesada, por ejemplo, en protestar, sino en actuar por mano propia” (Semana, 2016). La disminución de la credibilidad de la población en el sistema judicial, según Basombrío \& Dammert en Seguridad y populismo punitivo en América Latina (2013), está relacionada en la demanda social que reclama mayor sanción para el delincuente y parte de la percepción que los delitos y la impunidad están aumentando porque no hay castigo para los infractores, por lo que se reclama una mayor penalidad para quien cometa un delito y un aumento de control con el fin de mantener el orden social, entendiendo estas demandas que es responsabilidad de las instituciones de la justicia criminal la disminución del crimen y que la efectividad de la justicia penal no radica en el mejoramiento de los procesos de gestión, sino en el incremento del control a través de la penalidad.

Igualmente el funcionamiento del sistema de justicia penal bajo la visión tecnocrática recibe constantemente exigencias de demostración de la efectividad en su gestión mediante un crecimiento de la punitividad, bajo el crisol según el cual la pena aplicada y la ejecutada representan el mayor "indicador del desempeńo sobre la calidad de la justicia impartida en el sistema" (Basombrío \& Dammert, 2013, p. 5). Todo ello en un contexto social que relaciona la seguridad con la presencia policiva más que con el ejercicio de las garantías ciudadanas o la disminución de los grandes desequilibrios sociales, basado en la idea según la cual le corresponde a la Policía cumplir "el mandato y atribución del Estado para la mantención del orden público a través del uso legítimo de la fuerza" (Basombrío \& Dammert, 2013, p. 4) y en el que el sistema de justicia criminal es evaluado por criterios de eficiencia y eficacia con indicadores de logro de la gestión que "no van de la mano con el aumento de la calidad de la justicia" (Basombrío \& Dammert, 2013, p. 5) y cuyos resultados son usados con fines partidistas que exigen considerar la opinión de la ciudadanía en el proceso de justicia criminal.

Es en este contexto de presiones mediáticas, a las que está expuesta la función de los fiscales a quienes se les demanda más eficacia y eficiencia según el modelo de la empresa privada y al tiempo que respeten las garantías ciudadanas, que cabe preguntarse si la FGN debería continuar siendo parte de la rama judicial o ser parte del ejecutivo, y si tal modificación podría afectar positivamente la imagen que de esa institución y fortalecer la gestión de la rama judicial en la impartición de justicia, propuesta que ya desde 2012 la Corporación Excelencia en la Justicia ha venido liderando al buscar 
que la Fiscalía sea un ente autónomo de la rama judicial y esté liderada por un conocedor del tema y del procedimiento penal.

Los colombianos merecemos contar en el menor tiempo posible con un Fiscal General en propiedad, que satisfaga las expectativas de experticia, eficiencia, independencia y probidad. Una persona que tenga una corta curva de aprendizaje una vez asuma el cargo, de manera que se apropie pronto de la entidad, puesto que la necesidad de avanzar pronto en delicadas causas y superar las dificultades que actualmente presenta el sistema penal acusatorio y el sistema de responsabilidad penal de adolescentes, así lo requiere (El Nuevo Siglo, 2012).

Es de señalar que si bien la FGN hace parte de la rama judicial está obligada a suministrarle al Gobierno información sobre las investigaciones que está realizando según lo contempla el artículo 251, numeral 6 de la Constitución "cuando sea necesaria para la preservación del orden público" (Const., 1991) lo cual significa una especie de control del ente investigador por parte del ejecutivo al que le atribuye la Constitución "conservar el orden público en Colombia” (Pérez, 2014, p. 906). Esa cercanía entre la función policial del administrativo y la de persecución y acusación del delito de la Fiscalía es la razón por la cual algunos sectores han propuesto trasladar de la rama judicial a la rama ejecutiva a la FGN, buscando equilibrar las partes dentro del sistema penal acusatorio, aunque tal iniciativa hasta el momento ha sido desechada en el país. En 2012, la Corporación Excelencia en la Justicia propuso que el fiscal fuera designado por el presidente de ternas presentadas por la Corte Constitucional y que un requisito para ser fiscal general debía ser que demostrara experiencia relacionada con el cargo (El Nuevo Siglo, 2012). Elección Visible, que reúne varias organizaciones de la sociedad civil para hacer seguimiento a la nominación y elección de altos dignatarios de la justicia con el objeto de que se incorporen los más altos estándares de transparencia en esos procesos, presenta en su página web un cuadro en el que se compara la elección del fiscal en varios países y cómo en la mayoría de los países seleccionados hace parte de la rama ejecutiva o es independiente de las ramas de poder. Respecto de la designación de los fiscales en España donde también hace parte de la rama judicial, se han ventilado propuestas para que sean elegidos conforme el modelo estadunidense para que "cada ciudad y en cada Comunidad Autónoma fuese elegido por votación popular entre los residentes en la correspondiente circunscripción" y lograr con ello que la persona que tiene las riendas de la acusación criminal le responda al electorado (Blog Monsieur De Villefort, 2012). 


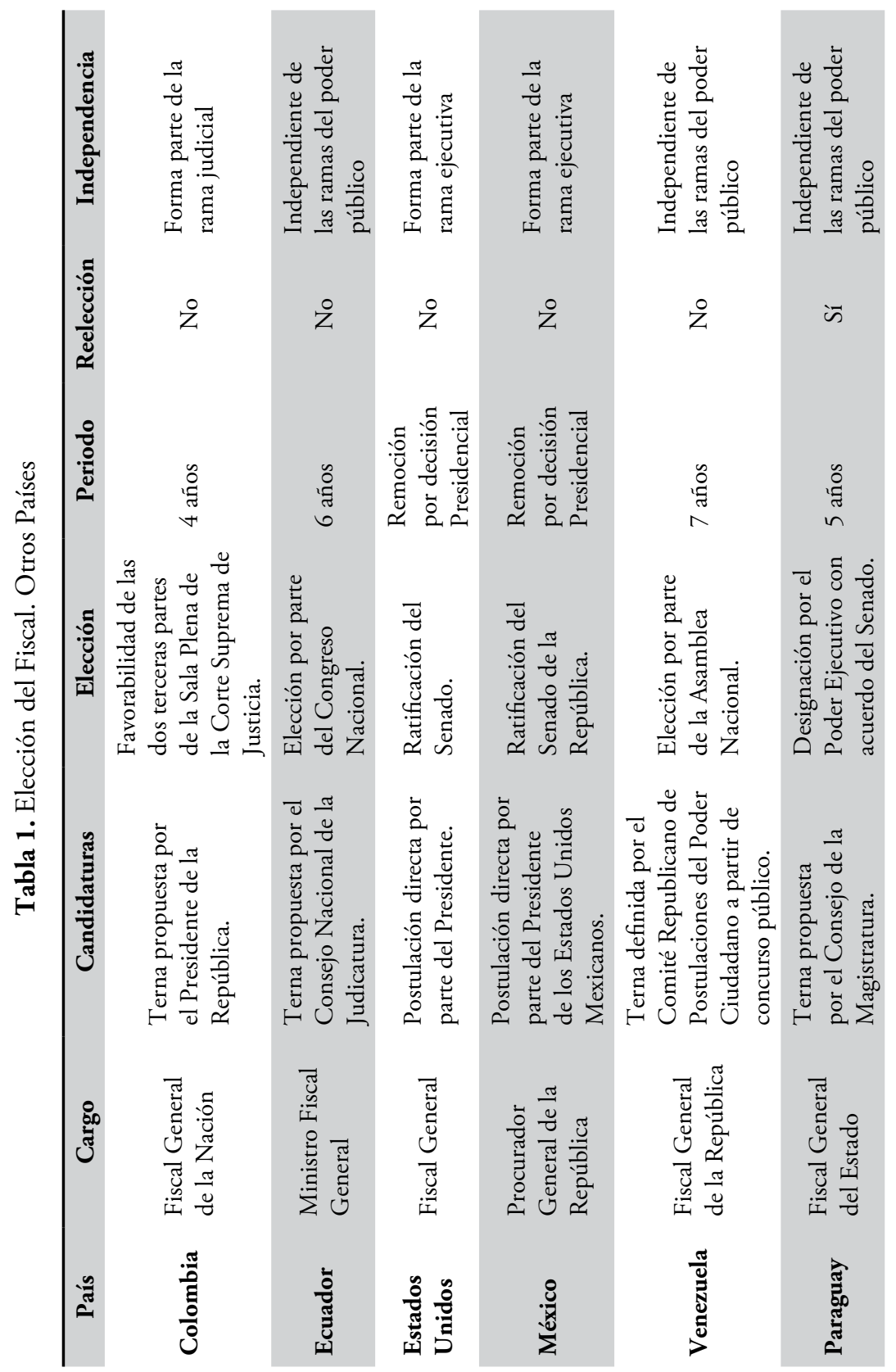




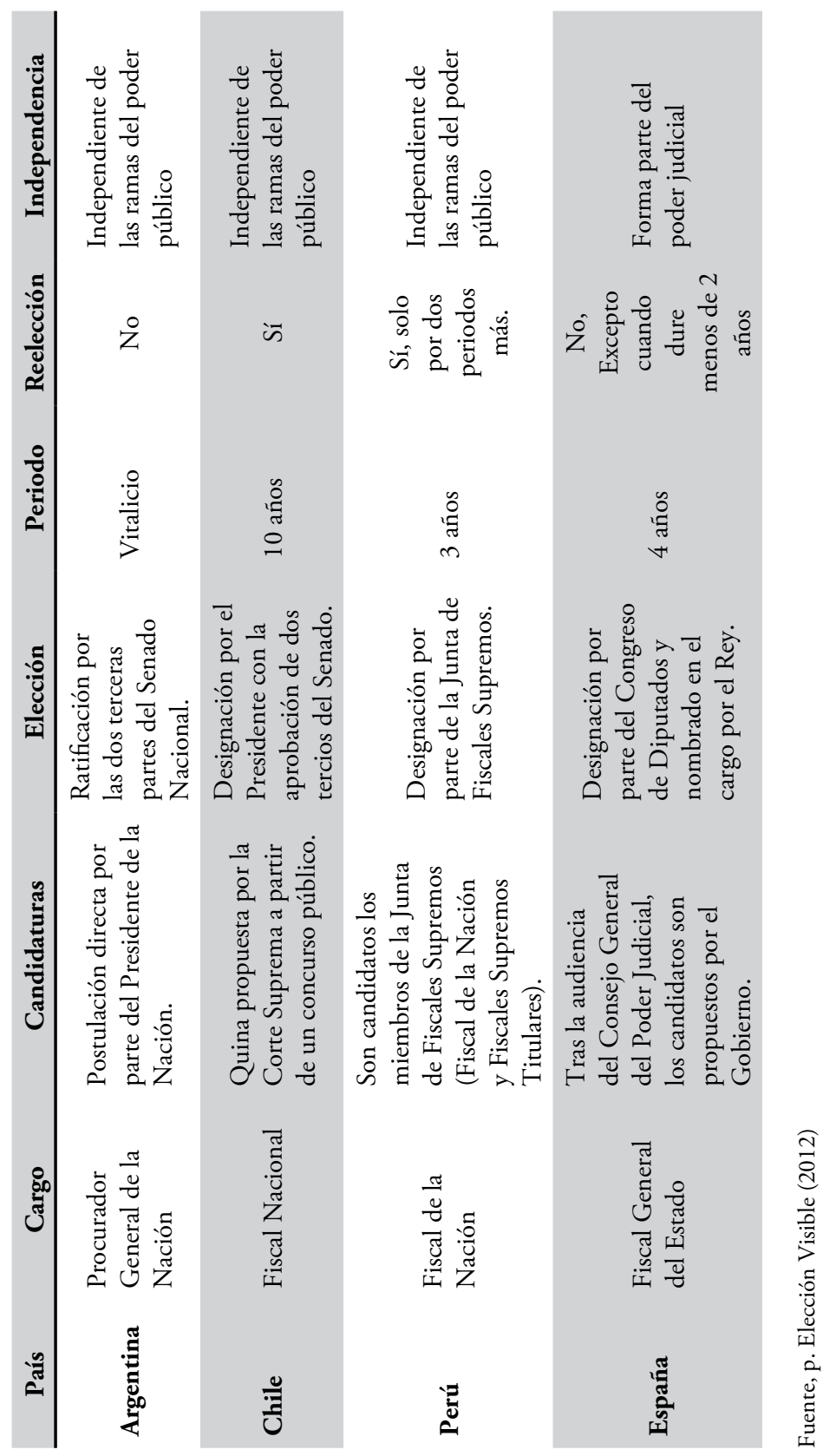


El efecto de concebir a la política criminal como la "obtención y realización de criterios directivos en el ámbito de la justicia criminal” (Cotes \& Fuentes, s.f., p. 65) es que se han incorporado nociones propias del sector privado a la gestión pública en las que se sobrevalora el concepto de seguridad en detrimento de la protección de las garantías ciudadanas contempladas en el sistema judicial vigente. Una muestra de ello se encuentra en la definición de la política criminal contenida en la Sentencia T-762/15, en la cual se le entiende como el conjunto de respuestas que el Estado acoge para enfrentar las conductas punibles teniendo como máxima "garantizar la protección de los intereses esenciales del Estado y de los derechos de los residentes en su jurisdicción" (79), supeditándose así a la política criminal bajo el alcance de la política de seguridad, todo ello con el fin de justificar un sinnúmero de restricciones a las garantías propias de la sociedad actual, siendo un ejemplo extremo de tal aplicación el uso de nociones propias de la teoría del derecho penal de enemigo.

A la luz de la obligación constitucional de la FGN de adelantar el ejercicio de la acción penal y realizar la investigación de los hechos que revistan las características de un delito cuando medien suficientes motivos y circunstancias fácticas que indiquen la posible existencia del mismo, el fiscal general debería liderar la formulación de políticas públicas en política criminal que tiendan al fortalecimiento de la capacidad investigativa de la institución y al mismo tiempo con las que se asegure el máximo respeto posible de los derechos fundamentales de los sujetos del mismo. Entendiendo por política pública el conjunto de decisiones o acciones, intencionalmente coherentes que diferentes actores públicos y privados adoptan a fin de resolver de manera puntual un problema políticamente definido como colectivo y que este "conjunto de decisiones y acciones da lugar a actos formales, con un grado de obligatoriedad variable" (Ministerio de Justicia y del Derecho Dirección de Política Criminal y Penitenciaria, 2014, p. 16) a fin de modificar el comportamiento de los grupos sociales en los que se origina el problema colectivo por resolver.

Las políticas públicas en política criminal que debe liderar la FGN deben centrarse en la carga laboral de los fiscales y en general del sistema judicial, mejorar la dotación de la institución y de la rama judicial, preocuparse por la capacitación e idoneidad de los investigadores con el firme propósito de buscar contribuir a la impartición de justicia y de respetar los derechos de las personas sindicadas o procesadas, evitándose la adopción de medidas de aseguramiento intramurales innecesarias o injustas. Porque 
hasta el momento, los fiscales están trabajando "con las uñas al no tener computadores, investigadores, fiscales de apoyo, y afrontan más de quinientos procesos sin mayor ayuda" (Cancino, 2016).

\section{Conclusiones}

Teniendo en cuenta que en esta investigación se buscaba mostrar cómo se ha venido justificando el desconocimiento o relativización de los Derechos Humanos bajo el supuesto que es la única medida que permite disminuir los índices delincuenciales en el país, tal como lo señala la reciente declaratoria de ECI del sistema penitenciario hecha por la Honorable Corte Constitucional en la sentencia T-762/15, puede concluirse que una de las primeras tareas que deben emprenderse en Colombia para asegurar el respeto de los Derechos Humanos a la población carcelaria, es precisar la capacidad real de los establecimientos de reclusión en las bases de datos del INPEC, adoptando como lo ordena la Sentencia T-762/15 unos estándares precisos sobre las condiciones mínimas que debe tener un cupo en tales establecimientos, teniendo en cuenta que tales estándares y la evaluación de los mismos debe enmarcarse en una política criminal coherente con los presupuestos de un Estado social de derecho como el colombiano.

En concordancia con lo ordenado en la Sentencia T-762/15, es imperativo que el Gobierno se comprometa en el fortalecimiento de una política criminal cimentada constitucionalmente, en la que se oriente a las autoridades públicas en el respeto de los derechos fundamentales de los investigados, procesados y condenados penalmente y con la cual se evite al máximo las demandas contra el Estado por falta de sustentación científica de las medidas judiciales adoptadas contra la ciudadanía. Partiendo de la idea, como lo hace la Sala de revisión, de que la política criminal debe tener un carácter preventivo, en la que el derecho penal sea usado como última ratio, especialmente en el tema referente a la adopción de medidas tendientes a restringir la libertad individual.

Ante el exceso de personas sindicadas privadas de la libertad en Colombia, debe recordarse que en la jurisprudencia constitucional reciente se ha reconocido un amplio espacio de configuración legislativa con el fin de señalar qué bienes jurídicos son 
susceptibles de protección penal, cuáles conductas deben ser objeto de sanción, las modalidades y la cuantía de la pena, teniendo como base la idea que es una prerrogativa sujeta a límites. Y que tales límites se enmarcan en el respeto a los derechos constitucionales de los asociados, en la obligación del Estado de respetar el principio de legalidad estricta y en los criterios de razonabilidad, proporcionalidad, tanto en la definición del tipo penal como a la sanción imponible, tal como lo menciona la Corte Constitucional en la Sentencia C-390/14 (p. 5).

\section{REFERENCIAS}

Basombrío, C. \& Dammert, L. (2013). Seguridad y populismo punitivo en América Latina: lecciones corroboradas, constataciones novedosas y temas emergentes. PDF. Series Editor: Cynthia J. Arnson. Woodrow Wilson Center update on the Americas. March 2013. Recuperado de: https://www.wilsoncenter.org/sites/default/files/Seguridad\%20y\%20 Populismo\%20Punitivo\%20en\%20America\%20Latina.pdf

Blog Monsieur De Villefort (2012). Fiscales por elección popular: origenes y desarrollo del sistema. Recuperado de: https://monsieurdevillefort.wordpress.com/2012/04/09/fiscales-por -eleccion-popular-origenes-y-desarrollo-del-sistema/

Cancino, I. (2016). “¿Un acto de cobardía?”. Los Irreverentes. Periodismo sin censura. Recuperado de: http://www.losirreverentes.com/-un-acto-de-cobard-a-.html

Carreño, Dalia (2016). "El sujeto activo en el delito de tortura en Colombia". En Derecho penal, vigilancia y control social, pp. 125-150. Bogotá: Editorial Ibáńez. Recuperado de: http://porticus.usantotomas.edu.co/bitstream/11634/1480/1/Derecho\%20penal\%2c \%20vigilancia\%20y\%20control\%20social.pdf

Colombia. Comisión Asesora de Política Criminal (2012). Informe final. Diagnóstico y propuesta de lineamientos de política criminal para el Estado colombiano, publicado en junio de 2012

Colombia. Congreso de la República (2014). Gaceta del Congreso 660 de 2014. Recuperado de: http://www.imprenta.gov.co/gacetap/gaceta.mostrar_documento?p_tipo=05\& p_numero $=1158$ p_consec $=40501$ )

Colombia. Congreso de la República (2000). Ley 599 de 2000, Código Penal. Recuperado de: http://www.secretariasenado.gov.co/senado/basedoc/ley_0599_2000.html) 
Colombia. Congreso de la República (2004). Ley 906 de 2004, Código Procesal Penal. Recuperado de: http://www.secretariasenado.gov.co/senado/basedoc/ley_0906_2004.html)

Colombia. Congreso de la República (2015). Ley 1760 de 2015, por la cual se modifica parcialmente la Ley 906 de 2004 en relación con las medidas de aseguramiento privativas de la libertad. Recuperado de: http://www.secretariasenado.gov.co/senado/basedoc/ ley_1760_2015.html

Colombia. Congreso de la República (2015). Ley 1753 de 2015, por la cual se expide el Plan Nacional de Desarrollo 2014-2018. 'Todos por un nuevo pais"'. Recuperado de: https:// www.youtube.com/watch?v=hzGL4jkQD7M)

Constitución política de Colombia (1991). En: http://www.secretariasenado.gov.co/index. php/leyes-y-antecedentes/constitucion-y-sus-reformas

Colombia. Corte Constitucional (2008). Sentencia C-425/08 del 30 de abril de 2008. Sala Plena. M.P. Marco Gerardo Monroy Cabra.

Colombia. Corte Constitucional (2013). Sentencia T-388/13 del 28 de enero de 2013. Sala Quinta de Revisión de la Corte Constitucional, M. P. Jorge Iván Palacio Palacio.

Colombia. Corte Constitucional (2013). Sentencia T-388/13 del 28 de junio de 2013. Sala Primera de Revisión, M. P. María Victoria Calle Correa.

Colombia. Corte Constitucional (2014). Sentencia C-390/14 del 26 de junio de 2014. Sala Plena. M.P. Alberto Rojas Ríos

Colombia. Corte Constitucional (2015). Sentencia T-762/15 del 16 de diciembre de 2015. Sala Quinta de Revisión, M.P. Gloria Stella Ortiz Delgado.

Colombia. Defensoría del Pueblo (2003). Análisis sobre el actual hacinamiento carcelario y penitenciario en Colombia. [Versión virtual en la página en internet de la Defensoría del Pueblo de Colombia].

Colombia. Defensoría del Pueblo (2015). Informe presentado por la Defensoría del Pueblo, el 22 de junio de 2015, en respuesta al auto expedido por la Sala Quinta de Revisión de tutelas. Folio 4 cd. Pruebas número 2. Sentencia T-762/15 del 16 de diciembre de 2015.

Colombia. Dirección Nacional de Planeación, DNP, (2010). Plan nacional de desarrollo 2010-2014. "Prosperidad para todos". Resumen Ejecutivo. Recuperado de: https://colaboracion.dnp.gov.co/CDT/PND/Resumen\%20Ejecutivo\%20Ultima\%20Version.pdf. 
Colombia. INPEC (2015). Informe estadístico de enero de 2015. Oficina asesora de planeación, grupo estadística. Bogotá, febrero de 2015. Recuperado de: http://www.inpec.gov. $\mathrm{co} /$ portal/page/portal/Inpec/Institucion/Estad\%EDsticas/Estadisticas/Informes $\% 20$ y\%20Boletines\%20Estad\%EDsticos/INFORME\%20ENERO\%202015\%201_0.pdf

Colombia. Ministerio de Justicia y del Derecho, Dirección de Política Criminal y Penitenciaria (2014). Lineamientos para el fortalecimiento de la política penitenciaria en Colombia, proyecto fortalecimiento y seguimiento a la politica penitenciaria en Colombia. Bogotá. Recuperado de: https://www.minjusticia.gov.co/Portals/0/sala\%20de\%20prensa/documentos/Lineamientos\%20sistema\%20penitenciario\%20\%20Consulta\%20WEB.pdf

Colombia. Ministerio de Justicia y del Derecho (2014). Subrogados penales, mecanismos sustitutivos de la pena y vigilancia electrónica en el sistema penal colombiano. Bogotá. Recuperado de: https://www.minjusticia.gov.co/Portals/0/sala\%20de\%20prensa/documentos/ Cartilla\%20Subrogados\%20Penales.pdf

Colombia. Ministerio de Justicia (2015). Intervención del 5 de junio de 2015. Folio 35 CD 1 de pruebas. Sentencia T-762/15 del 16 de diciembre de 2015.

Corte Interamericana de Derechos Humanos (2014). Informe sobre el uso de la prisión preventiva en las Américas. Recuperado de: http://www.oas.org/es/cidh/prensa/comunicados/2014/001.asp

Cotes M., Cindy P. \& Fuentes L., A. (s.f.). Populismo punitivo: incidencia actual en el contexto legislativo colombiano. PDF. Actualidad Jurídica. Facultad de Derecho en la Fundación Universidad del Norte. Barranquilla, Colombia.

Elección Visible (2016). Elección del Fiscal. Otros Países. Recuperado de: http://eleccionvisible.com/index.php/eleccion-fiscal-otros-paises

El Nuevo Siglo (2012). Fiscalía no haría parte de la rama judicial. Publicado el12 de marzo de 2012. Recuperado de: http://www.elnuevosiglo.com.co/articulos/3-2012 -fiscal\%C3\%AD-no-har\%C3\%AD-parte-de-la-rama-judicial.html

El Tiempo (2016). Congreso aprueba ponencia para frenar excarcelación de 4.000 presos. Publicado el 24 de mayo de 2016. Recuperado de: http://www.eltiempo.com/politica/ congreso/congreso-avanza-para-evitar-excarcelacion-masiva-de-presos/16601388) 
El Universal (2015). Colombia, el tercer pais con mayor impunidad en el mundo. Publicado el 21 de abril de 2015. Recuperado de: http://www.eluniversal.com.co/colombia/ colombia-el-tercer-pais-con-mayor-impunidad-en-el-mundo-191228

Pérez, V. J. (2014). Constitución política de Colombia, comentada. Bogotá: Editorial Leyer.

Rodríguez C. L. (2015). “¿Crisis en el modelo de administración de justicia?”. Congreso Mundial: Violencia, guerra y posconflicto. Pontificia Universidad Javeriana. Bogotá, 13 de noviembre de 2015. Recuperado de: http://www.ugc.edu.co/documentos/investigaciones/ presentaciones_congreso/crisis_modelo_administracion_justicia.pdf

Rubio, E. J. V. (2015). "La doctrina penal del papa Francisco". Portal virtual: Abogado Roberto Spinetti. Recuperado de: http:/www.robertospinetti.com/\%20/ la-dottrina-penale-del-papa-francesco/?lang=es

Semana (2015). Los 22.000 presos sin pena que saldrian de la cárcel. Publicado en junio 20 de 2015. Recuperado de: http://www.semana.com/nacion/articulo/los-22000 -presos-sin-pena-que-saldrian-de-la-carcel/432037-3)

Semana (2016). La mujer que desnudó al ladrón: ¿Exceso o legítima defensa? Publicado en mayo 26 de 2016. Recuperado de: http://linkis.com/www.semana.com/nacio/QGxjN)

Wemer, M. (2014). “Derecho papal”. Publicado en el Diario Judicial, el 02 de junio de 2014. Recuperado de: http://www.diariojudicial.com/nota/34406 